\title{
Patient global assessment to define remission in rheumatoid arthritis: quo vadis?
}

\author{
Maarten Boers (10) 1,2
}

The American College of Rheumatology/ European League Against Rheumatism (ACR/EULAR) preliminary criteria for remission in rheumatoid arthritis (RA) have found widespread endorsement and adoption since their publication in 2011 (box 1). ${ }^{1}$ Patients that fulfil the criteria are almost indistinguishable from healthy persons and live a normal life. ${ }^{2}$ Nevertheless, the criteria are also seen as too strict, ${ }^{3}$ as not including enough patient-important outcomes $^{4}$; and their application in patient care, as advised by guideline committees, has problems. Most of the criticism focuses on the inclusion of patient global assessment (PGA) and its threshold.

In principle, these (perceived or real) limitations can be explained by re-examining the purpose and the development process of the criteria. And then solutions can be sought.

First of all, the committee was tasked with developing criteria that included, as a minimum, tender and swollen joint counts, and was strict, to counter existing criteria that failed to define remission. ${ }^{1}$ So the strictness of the current criteria 'is not a bug, but a feature' as Bill Gates may have said when his problematic software was discussed. More seriously, patients close to, but not in remission, can be classified as having 'minimal disease activity' for which the Outcome Measurement in Rheumatology (OMERACT) initiative already formulated a set of definitions in $2005.5^{5}$ Briefly, patients can be considered in minimal disease activity if they meet five out of seven criteria (tender joint count $\leq 1$; swollen joint count $\leq 1$; health assessment questionnaire $\leq 0.5$; pain $\leq 2$; physician global assessment $\leq 1.5$; $\mathrm{PGA} \leq 2.0$; erythrocyte sedimentation rate $(\mathrm{ESR} \leq 20)$. Unfortunately, this concept has not gained much traction in guidelines, leaving a gap

\footnotetext{
${ }^{1}$ Epidemiology \& Data Science, Amsterdam UMC, Vrije Universiteit, Amsterdam, The Netherlands

${ }^{2}$ Amsterdam Rheumatology and Immunology Center, Amsterdam UMC, Vrije Universiteit, Amsterdam, The Netherlands
}

Correspondence to Professor Maarten Boers, Epidemiology \& Data Science, Amsterdam UMC, Vrije Universiteit, Amsterdam 1081 HV, Netherlands; m.boers@amsterdamumc.nl between 'low disease activity' and 'remission', even though it would arguably be a good target for treatment: more stringent than low disease activity and more feasible than remission.

Since then, several publications have pointed out that many patients fail to meet the remission criteria only because their PGA score is above 1 (on a scale of $0-10$ ), see for example Ferreira et al, ${ }^{6}$ and that of such patients, those with a PGA score of 2 closely resemble patients fully in remission. ${ }^{3}$ Also, the Simplified Disease Activity Index definition of remission already is slightly less strict and includes such patients. ${ }^{7}$ In addition, in many countries PGA is measured on a $0-100$ scale, and it is unclear what the threshold should be on that scale: in theory patients scoring ' 1 ' on a scale from 0 to 10 could have a score of 14 or even 15 on a scale of $0-100$ (depending on which rounding rule is favoured). Finally, our group is preparing a report that shows that patients themselves will frequently consider themselves in remission while scoring 2 on their PGA
(Rasch et al, in preparation). All of these findings suggest the PGA threshold could be slightly relaxed, bringing more congruence to the two versions of the remission definition without changing the essence, a strict definition that identifies people who can live a normal life. In my view, it is important that this characteristic stays in place. Any amended definition would have to be very specific about the threshold on the $0-100$ scale: that is, '20'. It is my understanding that ACR and EULAR will soon start an initiative in this direction.

A second and more principal point is the intended purpose of the criteria, and how they have been applied since. From the outset, the criteria were intended for use in research, especially clinical trials, to define a subgroup of patients that were doing optimally well. However, in the publication, this purpose was somewhat weakened by the suggestion (in the discussion) that the criteria could be of use in patient care. Initially, subsequent treatment guidelines suggested treat to target as the new standard, with remission the target. And it is exactly here that things have started to derail.

Most importantly: although ACR/ EULAR remission rates are on the increase, both in recent trials and in cohorts, to date our treatments (including traditional disease-modifying antirheumatic drugs (DMARDs), glucocorticoids, biologics and synthetic targeted DMARDs) are simply not good enough to reach that target in the majority of patients. Second,

Box 1 American College of Rheumatology-European League Against Rheumatism remission criteria.

Boolean-based definition

At any time point, patient must satisfy all of the following: Tender joint count $\leq\left.\right|^{*}$ Swollen joint count $\leq 1^{*}$

$C$ reactive protein $\leq 1 \mathrm{mg} / \mathrm{dL}$

Patient global assessment (PGA) $\leq 1$ (on a $0-10$ scale) $\dagger$

Index-based definition

At any time point, patient must have a Simplified Disease Activity Index Score of $\leq 3.3 \ddagger$

*For tender and swollen joint counts, use of a 28 -joint count may miss actively involved joints, especially in the feet and ankles, and it is preferable to include feet and ankles also when evaluating remission.

tFor the assessment of remission we suggest the following format and wording for the global assessment questions. Format: a horizontal $10 \mathrm{~cm}$ visual analogue or Likert Scale with the best anchor and lowest score on the left side and the worst anchor and highest score on the right side. Wording of question and anchors: For PGA, 'Considering all of the ways your arthritis has affected you, how do you feel your arthritis is today?' (anchors: very well-very poor). For physician/assessor global assessment, 'What is your assessment of the patient's current disease activity?' (anchors: none-extremely active).

$\ddagger$ Defined as the simple sum of the tender joint count (using 28 joints), swollen joint count (using 28 joints), PGA (0-10 scale), physician global assessment (0-10 scale) and C reactive protein level (mg/ $\mathrm{dL})$. 
in patients that are already in a state of minimal disease activity, there is little or no evidence to show that treatment intensification does more good than harm. Third, none of our current measurement tools are good enough to reliably detect or exclude residual disease activity that should be treated. Most current objections against the remission criteria are levelled at the validity of PGA (i.e., whether it measures disease activity or 'impact'), but the same goes for joint counts and acute phase reactants, as these also lack specificity and reliability in low disease activity states. Acute phase reactants are especially problematic in the assessment of treatments targeting interleukin 6 and pathway inhibitors. ${ }^{8}$ More advanced tools such as sonography or MRI have not proven to be better in improving outcome in clinical trials, under optimum conditions, ${ }^{9-11}$ so they cannot be recommended for this purpose in routine clinical practice.

Simply stated, we can now get most patients into a 'good' (minimal disease activity) state, but, once they are there:

- We do not know for sure whether that state is good enough.

- We do not have the treatments to move patients into a better state than 'good'.

- Even if we had such treatments, we do not have the tools to reliably measure success of treatment intensification in patients in a 'good' state.

The learned societies have taken note of the above considerations, and the most recent updates include 'low disease activity' as a target in addition to 'remission'. ${ }^{12}$ As stated above, I hope in the next updates 'low disease activity' will be replaced by 'minimal disease activity'.

The validity of a state (such as remission) as defined by a committee of experts can be questioned: what does it really mean, and how important is it to be in that state? In the development, the committee decided to use follow-up data from clinical trials and assess two external anchors: good damage outcome (on X-rays of hands and feet), and good functional outcome (as measured by the Health Assessment Questionnaire). It then examined candidate definitions on their capability to predict these outcomes, and the current remission definition emerged as one of the top performers. ${ }^{1}$ Although I am convinced that this was a good approach, it can and has been criticised. In any case, the current definition is an evidence-based agreement of experts.

Since then several studies have tried to replicate the results, with varying success. The main 'problem' of those studies and of most patients with RA currently under treatment is that treatment has improved so much. As a consequence, the rate and extent of damage progression has progressively decreased in the last 20 years; and because everyone is doing so well, it has become very difficult to detect contrasts between groups of patients. The same goes for functional decline. Thus, most patients will have good damage and functional outcome, at least for a couple of years, whether or not they are in 'full' remission, as long as they do not have really active disease over an extended period of time. In sum, our external anchors to detect the effects of being in different disease states (e.g., remission according to different definitions) have become less useful, mostly because the quality of treatment has gone up, and extended periods of high disease activity have become rare.

It is in this setting that Ferreira et al have embarked on a long journey to disentangle disease activity from impact, and to revise the remission criteria for use in patient care. Previously they have shown in the Etude et Suivi des Polyarthrites Indifférenciées Récentes (ESPOIR) cohort that the current definition has only numerical advantages over a definition without PGA to predict lack of damage progression. ${ }^{14}$ They posit that disease activity should be measured with joint counts and acute phase reactants, and treated with DMARDs; impact should be measured with PGA and treated with other interventions. In this issue of the Annals, they present the results of an individual patient meta-analysis, where they compare the predictive performance (for good damage and functional outcome) of the original remission criteria with two alternatives that do not include PGA. $^{15}$ They conclude that PGA has little to add for damage outcome, but a lot for functional outcome. From their perspective, functional outcome is strongly related to impact independent of disease activity, so that this result is of little value to decide on a remission definition in practice.

I applaud Ferreira et al for so forcefully driving this important discussion, and all the beautifully conducted studies they have done to address these important issues. However, I mostly disagree with their conclusions, and with the idea that PGA should be taken out of considerations on disease activity. First of all, in the current study, the current remission definition performed better than their proposed alternatives, sometimes significantly, sometimes numerically. Second, in the ESPOIR study rapid damage progression was only seen in patients with a high PGA. ${ }^{14}$ Third, the whole idea that an individual clinician and a patient would be completely bound by a remission definition to decide whether or not to escalate or switch treatment (in their words, causing 'overtreatment' of patients suffering only from impact, not disease activity) is overly simplistic. In our own clinic, treat-to-target trials ran into difficulties with physicians and patients not adhering to protocol-mandated intensification decisions when disease activity was low or minimal. ${ }^{16}$ In clinical practice, several studies have shown that absence of 'objective' signs of inflammation, such as an isolated elevated PGA was the most frequent reason for deviations from advancing therapy in a treat to target setting. ${ }^{17} 18$ In other words, rigid focus on remission as target is unlikely in routine clinical practice. In fact, lack of adherence to systematic measurement of disease status and treat to target schedules, that is, undertreatment, is probably more of a problem than the converse. ${ }^{19}$ Finally, any disadvantages of the current definition can be repaired with less rigorous measures, as suggested above. I do agree that more efforts should be focused on understanding and addressing patient need in the area of impact: some impact may indeed be independent of disease activity, but I suspect there is still a part that reflects undetected residual disease activity, perhaps not detectable by other means.

\section{Handling editor Josef S Smolen}

Funding The authors have not declared a specific grant for this research from any funding agency in the public, commercial or not-for-profit sectors.

Competing interests None declared.

Patient and public involvement Patients and/or the public were not involved in the design, or conduct, or reporting, or dissemination plans of this research.

Patient consent for publication Not required.

Provenance and peer review Commissioned; internally peer reviewed.

(C) Author(s) (or their employer(s)) 2021. No commercial re-use. See rights and permissions. Published by BMJ.

Check for updates

To cite Boers M. Ann Rheum Dis 2021;80:277-279.

Received 6 October 2020

Revised 19 October 2020

Accepted 19 October 2020

Published Online First 6 November 2020

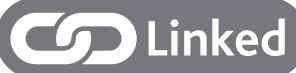

- http://dx.doi.org/10.1136/annrheumdis-2020 217171

Ann Rheum Dis 2021;80:277-279.

doi:10.1136/annrheumdis-2020-218802

ORCID iD

Maarten Boers http://orcid.org/0000-0002-6969-283X 


\section{REFERENCES}

1 Felson DT, Smolen JS, Wells G, et al. American College of Rheumatology/European League against rheumatism provisional definition of remission in rheumatoid arthritis for clinical trials. Ann Rheum Dis 2011;70:404-13.

2 Radner H, Smolen JS, Aletaha D. Remission in rheumatoid arthritis: benefit over low disease activity in patient-reported outcomes and costs. Arthritis Res Ther 2014; 16:R56.

3 Studenic P, Smolen JS, Aletaha D. Near misses of ACR/ EULAR criteria for remission: effects of patient global assessment in Boolean and index-based definitions. Ann Rheum Dis 2012;71:1702-5.

4 van Tuyl LHD, Smolen JS, Wells GA, et al. Patient perspective on remission in rheumatoid arthritis. J Rheumatol 2011;38:1735-8.

5 Wells GA, Boers M, Shea B, et al. Minimal disease activity for rheumatoid arthritis: a preliminary definition. J Rheumatol 2005;32:2016-24.

6 Ferreira RJO, Duarte C, Ndosi M, et al. Suppressing inflammation in rheumatoid arthritis: does patient global assessment blur the target? A practice-based call for a paradigm change. Arthritis Care Res 2018;70:369-78.

7 Studenic $P$, Felson $D$, de Wit $M$, et al. Testing different thresholds for patient global assessment in defining remission for rheumatoid arthritis: are the current ACR/EULAR Boolean criteria optimal? Ann Rheum Dis 2020;79:445-52.
8 Smolen JS, Aletaha D. Interleukin-6 receptor inhibition with tocilizumab and attainment of disease remission in rheumatoid arthritis: the role of acute-phase reactants. Arthritis Rheum 2011:63:43-52.

9 Haavardsholm EA, Aga A-B, Olsen IC, et al. Ultrasound in management of rheumatoid arthritis: ARCTIC randomised controlled strategy trial. BMJ 2016;354:i4205

10 Dale J, Stirling A, Zhang R, et al. Targeting ultrasound remission in early rheumatoid arthritis: the results of the TaSER study, a randomised clinical trial. Ann Rheum Dis 2016;75:1043-50.

11 Møller-Bisgaard S, Hørslev-Petersen K, Ejbjerg B, et al. Effect of magnetic resonance imaging vs conventional Treat-to-Target strategies on disease activity remission and radiographic progression in rheumatoid arthritis: the IMAGINE-RA randomized clinical trial. JAMA 2019;321:461-72

12 Singh JA, Saag KG, Bridges SL, et al. 2015 American College of rheumatology guideline for the treatment of rheumatoid arthritis. Arthritis Rheumatol 2016;68:1-26.

13 Smolen JS, Landewé RBM, Bijlsma JWJ, et al. EULAR recommendations for the management of rheumatoid arthritis with synthetic and biological diseasemodifying antirheumatic drugs: 2019 update. Ann Rheum Dis 2020;79:685-99.

14 Ferreira RJO, Fautrel B, Saraux A, et al. Patient global assessment and radiographic progression in early arthritis: 3-year results from the ESPOIR cohort.
Arthritis Care Res 2020. doi:10.1002/acr.24237. [Epub ahead of print: 27 Apr 2020]

15 Ferreira RJO, Welsing PMJ, Jacobs JWG, et al. Revisiting the use of remission criteria for rheumatoid arthritis by excluding patient global assessment: an individual meta-analysis of 5792 patients. Ann Rheum Dis 2021;80:293-303.

16 ter Wee MM, den Uyl D, Boers M, et al. Intensive combination treatment regimens, including prednisolone, are effective in treating patients with early rheumatoid arthritis regardless of additional etanercept: 1-year results of the COBRA-light openlabel, randomised, non-inferiority trial. Ann Rheum Dis 2015;74:1233-40.

17 Zak A, Corrigan C, Yu Z, et al. Barriers to treatment adjustment within a treat to target strategy in rheumatoid arthritis: a secondary analysis of the traction trial. Rheumatology 2018;57:1933-7.

18 Sepriano A, Ramiro S, FitzGerald 0, et al. Adherence to Treat-to-target management in rheumatoid arthritis and associated factors: data from the International RA BIODAM cohort. J Rheumatol 2020;47:809-19.

19 Ramiro S, Landewé RBM, van der Heijde D, et al. Is treat-to-target really working in rheumatoid arthritis? A longitudinal analysis of a cohort of patients treated in daily practice (RA BIODAM). Ann Rheum Dis 2020;79:453-9. 